openUP

\title{
Factors motivating consumers to engage in direct purchasing
}

Yolanda Jordaan

Direct marketing is seen as a growing industry in South Africa. In recent years, socio-economic trends, such as changing social patterns and technological advances, have favoured the development of direct marketing. Marketers are entering an era of individualisation in which many of today's consumers are informed buyers. To understand consumers' reasons for direct purchasing, focus has been placed on consumers' buying motives. The purpose of this article is therefore to explore the factors motivating South African consumers to use direct purchasing as a shopping method. Special attention is given to consumers' attitudes toward direct purchasing. The findings of a research survey presentthe most important motivational factors of direct purchasing. Although the study is of an exploratory nature, hypotheses were formulated based on the available literature and the findings of studies conducted previously in other countries. The main findings indicate that perceived risks are some of the most powerful discriminators between direct purchasers and non-direct purchasers.

Keywords: consumers; direct marketing; direct purchasing; motivational factors; marketing communication

Direct marketing is an interactive system of marketing that communicates directly with customers to effect a measurable response and/or transaction (Power, Balderstone \& Gyles, 2000). In recent years, socio-economic trends, such as changing social patterns and technological advances, have favoured the development of direct marketing. Regrettably, it appears that there is little or no empirical research on the size of the direct-marketing industry in South Africa, but practitioners believe that the use of direct marketing is growing in South Africa (Anon, 2001). Increasing consumer interest and a wide application of direct-marketing techniques are rendering the direct-marketing industry increasingly competitive (Schoenbachler, Gordon, Foley \& Spellman, 1997). 
Many customers are now demanding more than they did in the past. They are searching for products and services that meet their individual needs; they do not want to be categorised and wish to remain in control (Prabhaker, Sheehan \& Coppett, 1997). This attitude presents marketers with opportunities as well as with a responsibility to deal with customers as individuals. It also serves as a motivation for the development of new products and services to satisfy individuals' needs. This has led to a change from the general selling approach to an approach demanding a more sophisticated marketing orientation.

The purpose of this article is to explore the attitudes of South African consumers toward direct purchasing empirically. Here, an attitude is defined as an individual's enduring perceptual, knowledge-based, evaluative and action-orientated processes with respect to direct purchasing (Kinnear \& Taylor, 1996). For the purpose of the research, emphasis was placed on the three components of attitudes, namely, the cognitive, affective and behavioural components. A better understanding of consumers' attitudes can enable direct marketers to develop products and services in line with consumers' needs, and can improve the ways in which they present the products and services to target segments. This article places direct marketing in perspective by focusing on past, present and future trends in this field. Findings from previous direct-marketing studies are also presented before a discussion on current research is provided. The objective of the study is to explore the factors motivating South African consumers to consider direct purchasing. The data analyses consist of Mann-Whitney tests as well as a discriminant analysis. The findings of the study identify six motivational factors that distinguish consumers who buy directly from those who do not.

\section{DIRECT MARKETING IN PERSPECTIVE}

In a world where it has become more difficult to control marketing efforts, direct marketing has a considerable contribution to make. When properly managed, it is easier to control than less disciplined marketing activities (Holtz, 1986). Anumber of sources have reported on the growth of direct marketing (Belch \& Belch, 1990; Power et al., 2000; Stone, 1979; Tapp, 1998). Some of the factors that have contributed to the growth of the direct-marketing industry are:

(a) Direct-marketing indicators: Organisations that specialise in developing name and address lists, inserts and catalogues have created new opportunities and contributed to the growth of direct marketing. More sophisticated marketing techniques and a better image of the industry have contributed to the increased effectiveness of direct marketing (Thomas \& Housden, 2002).

(b) The changing nature of the community and the market: The increase in dualincome families has placed greater emphasis on recreational activities, doit-yourself products and home entertainment. Less time is available for shopping and direct purchases have become more attractive. Customers 
increasingly want the option of contacting organisations directly, leading to a greater appreciation of the convenience of direct marketing (Lavin, 1993).

(c) Technological progress: The development of electronic media and computer technology has eased the burden of shopping, and has made it easier for marketers to reach their desired target markets. Direct marketing to people athome is regarded as one ofthe fastest-growing forms of distribution, which will grow even faster with the emergent electronic technologies. Many people regard e-business as a revolution that is transforming the way business is done. There are many signs that there will be a growing shift in expenditure in the direction of direct marketing over the Internet and e-mail marketing in particular. There are three main reasons for this: The first is that the cost of mounting an advertising campaign on the Internet entails a fraction of the cost of using traditional media. The second is the sales conversion ratios for e-mail marketing being 5 to $15 \%$, compared to 0.5 to $2 \%$ for conventional mailings. Lastly, there is a trend towards e-mail marketing at the expense of banner advertising (Gauthronet \& Drouard, 2001). To experienced direct marketers, e-business is an extension of what they have practised in the past. New technology enables them to execute it even more efficiently and costeffectively (Roberts, Feit \& Bly, 2001).

(d) Pressure for cost-effectiveness: Direct marketing has the ability to track individual orders and therefore measure the effectiveness of specific marketing actions. By knowing precisely which offers had successful results and which did not, the marketer can allocate the marketing budget more effectively (Roberts \& Berger, 1999). One ofthe main reasons for direct marketing's increasing popularity among marketers, who need to reduce overheads and are uncertain ofthe yields of general advertising, is that direct marketing can be measured (Crumbley, 1994). Its ability to control orders can lead to better targeting and campaign measurement. Many companies view direct marketing as a way of adding value to their markets and differentiating their offerings.

(e) Problems with retail shopping: Certain problems experienced by consumers in retail shopping, such as poor parking facilities, uninformed sales staff, crowding at peak times and long queues at pay-points have also contributed to the growth of direct marketing. One ofthe latest concerns of many shoppers is the potential danger of becoming a crime victim in the shopping environment. Compared to shopping at a retail store, customers who purchase products directly through media such as the telephone, mail or Internet, are not exposed to violent crimes such as car bombs, car theft, hij ackings or muggings. Consumers can do their shopping from the comfort and safety of their homes by means of either mail-order catalogues, direct-response television or the Internet (Humphrey, 2000). 
Direct marketing is therefore becoming a popular medium of the twenty-first century, as seen by the emphasis being placed on direct response through the use of television, telemarketing, and direct response in print media and Internet direct mail. A shift is taking place from an industrialised community to an information-based community. Marketers are entering an era of individualisation in which many of today's consumers are informed buyers with the power to make informed choices (Schoenbachler et al., 1997). In marketing communication the emphasis must therefore move from intrusion, to information, to instruction that prompts an invitation to purchase. Future consumers will have the technology to take charge of the marketing communication received. They will decide for themselves what communication to see, read and hear, and when to react to communication offerings (Anon, 1993).

Toll-free numbers, expanding productivity, improved database management, direct-ordering services and increasing lists of choices offer the South African directmarketing industry an exciting future. Massive customer databases will create anew level of effectiveness, and contribute towards continuous dialogue with the end-users of products and services.

Of all the professional challenges facing direct marketers, none will be greater than the need to elevate direct marketing to a higher level and to endeavour to develop a better product, to a better-targeted audience, at a better price, with better results. Databases play a significant role in the success of direct marketing through the use of direct mail, telemarketing, and the Internet. Proper identification of customers and prospects, demographic and psychographic information, and data reflecting the recency and frequency of purchases will form the basis on which marketers will be able to compete (Stewart, 1992). In order to utilise a database properly, direct marketers need to understand the typical direct shopper. The next section therefore documents attempts by researchers to understand direct shoppers' purchase intentions.

\section{ATTITUDES TOWARD DIRECT MARKETING AND PURCHASE INTENTIONS}

Direct marketing has all the ingredients for a successful business operation. It is fast-paced, rewarding, results-orientated and offers several opportunities for growth. These characteristics indicate why researchers have attempted to measure its effect on consumers' behaviour (McDonald, 1993).

Several researchers have measured frequent direct-marketing patronage to identify factors that are associated therewith. Some of these studies have focused on the demographics of direct purchasers (Cunningham \& Cunningham, 1973; Eastlick \& Feinberg, 1994; Jayawardhena, Wright \&Masterson, 2003; Lavin, 1992, 1993; Milne \& Gordon, 1994; Settle, Alreck \& McCorkle, 1994). Demographics per se are not sufficient for understanding consumers' motivation for direct purchasing. Consumers' buying motives also need to be taken into account. These are the internal forces 
that cause consumers to seek out, evaluate, and make purchase decisions (Peltier \& Schribrowsky, 1992).

Several international studies have focused on non-demographic indicators as determinants of direct-shopping behaviour, for example, attitudes, perceptions and motivations. Some studies have identified perceived risk as a motivational factor for direct purchasing (Ghert, Yale \& Lawson, 1996; Jarvenpaa \& Todd, 1997; Park \& Stoel, 2002; Reynolds, 1974; Vrjayasarathy \& Jones, 2000). Such perceptions may range from high levels of perceived risk to no difference in perceived risk between direct purchasers and store purchasers. Ghert, Yale and Lawson (1996) advise direct marketers to be particularly attentive to convenience concerns that may arise during the direct-purchasing process. The results indicate that direct shoppers tend to perceive risk when in the process of ordering, receiving, and returning purchased goods.

Several researchers have also found convenience to be a principal reason for favouring non-store retail methods (James \& Cunningham, 1987; Kaufman-Scarborough \& Lindquist, 2002; Lavin, 1993; McCorkle, Planchon \& James, 1987). Women entering the workforce have been cited as one of the reasons for the growth in direct marketing. Berry and Cooper (1990) have identified the increase in women in the labour force as primary contributors to time pressure which, in turn, could lead to a preference for non-store buying. However, the results of a study by Lavin (1993) indicated that for both husbands and wives, strong feelings of time pressure were not associated with an increased preference for non-store purchasing.

Findings by Akhter and Durvasula (1991) suggest that various combinations of attitudes toward the elements of direct marketing affect purchase intentions. Furthermore, the findings posit that attitudes toward catalogues and ordering by mail are more important than attitudes toward the direct-marketing company in distinguishing between those with favourable purchase intentions and those with unfavourable purchase intentions. This was supported by Kaufman-Scarborough and Lindquist's (2002) research, which indicates that there is a positive relationship between the frequency of online shopping and the frequency of using other forms of non-store shopping. A study by Donthu and Gilliland (1996) found that direct-television shoppers (consumers who phone in to purchase after seeing a direct-response television commercial) tend to be less risk-averse, more price-conscious, and more convenience-seeking than non-television shoppers. They are also more brand-conscious, innovative, impulsive, and variety-seeking than non-television shoppers and have a more negative attitude toward general shopping and a more positive attitude toward direct marketing.

A South African study by Terblanche, Boshoff and Smit (1999) identified eight motivational dimensions for mail-order catalogue purchasing, namely, time-saving, fun, credit arrangements, spectrum of merchandise offered, cost-saving, uniqueness of the merchandise offered, information needed for decision-making and prevention of embarrassment. Several studies have also addressed the issue of privacy concerns and consumers' reluctance to provide personal information (Long, Hogg, Hartley \& Angold, 1999; Mann, 1997; Park \& Kim, 2003; Phelps, Nowak \& Ferrel, 2000; Sahd, 
1998; Wang \& Petrison, 1993). Evidence from these studies shows that consumer attitudes about marketers' use of their personal information varied depending on the situation, the perceived reputation of the company using the information, and the relevance of the products being sold for consumers' own personal needs and wants. These studies have emphasised the need for privacy legislation as well as for the use and promotion of self-regulatory policies and practices by direct marketers.

The results from a study by Vrjayasarathy and Jones (2000) contributed to knowledge of Internet shoppers by indicating that consumers' attitudes and intentions are influenced by factors such as product value, shopping experience, perceived risk and customer service. The identification of motivational factors is perhaps more important today than it was in the past, since marketing has to adapt to an ever-changing marketplace where there is a constant evolution of consumer preferences, buying habits and technology, while coping with pressures from competitors (McDonald, 1993).

Based on the preceding literature review, the following motivational factors for direct purchasing are investigated in this study: time-saving, convenience, privacy of mail orders, privacy of telephone orders, general risk perception, financial risk, performance risk, time-loss risk, social risk, special offers, free items offered, variety of products available, price consciousness, credit-card usage, urgency of advertisements, and provision of toll-free numbers.

\section{METHOD}

\section{Sampling}

A probability sampling design was used to draw a sample of 4000 clients from a direct-insurance company's database. A simple random sample was selected from the sampling frame (company database) using random number tables. The individuals on the database were assigned a number. Thereafter, a sample of these numbers was then selected by the use of a random number table. The data were collected by means of a mail questionnaire, consisting of a six-page questionnaire, apre-paid return envelope and a cover letter. Respondents were either people who had purchased directly from the company, or had reacted telephonically to a direct-response advertisement. From a total of 4000 questionnaires, 2000 were mailed to current clients, and the other 2000 to previous or potential clients. The effective response rate of the mail survey was approximately 13\% (557 questionnaires).

\section{Measurement instrument}

The main body of the questionnaire consisted of 16 evaluative statements concerning the measurement of respondents' attitudes toward direct purchasing. For the purpose of the study, attitudes were measured by focusing on individuals' awareness and knowledge of direct purchasing (cognitive component), their feelings towards direct purchasing (affective component) and their expectations of possible future actions 
towards direct purchasing (behavioural component). The questionnaire was pre-tested during a pilot study before it was sent to respondents in the sample. The questionnaire consisted mainly of 5-point bipolar Likert scales where 1 represented a 'strong disagreement' and 5 a 'strong agreement' with the individual statements. Some of the statements were stated in the negative to ensure that respondents used both ends of the Likert scale. It was emphasised that direct purchasing included any product or service that was ordered or purchased via the telephone or by mail. Only respondents who had already purchased directly, or had reacted telephonically to direct-response advertisements, were targeted. Internet shopping was not considered at the time because of the relatively low usage of the medium for direct-purchasing purposes.

\section{Data analysis}

The data analyses were done in the following order: A Mann-Whitney test was performed to test for differences between direct purchasers and non-direct purchasers. The respondents who answered yes to the question 'would you buy directly again?' were classified as direct purchasers $(n=90)$. All respondents who answered no or uncertain to this question, were classified as non-direct purchasers because the 'no' group would not purchase directly again, and it was not clear whether the 'uncertain' group would buy directly again $(n=139)$. The significance criterion to test the hypotheses was set atp $<0.05$ (at least $95 \%$ confidence).

Thereafter, a discriminant analysis was performed in an attempt to identify which aspects most strongly determine direct purchasers' attitudes. Discriminant analysis examines an entire profile of characteristics common to a group of purchasers, as well as the interaction of these properties, and transforms them into a univariate statistic. The results emerging from the study indicate the motivational factors driving South African direct purchasers. The following hypotheses were formulated:

HI: Direct purchasers will perceive direct purchasing as a shopping method that saves time.

H2: Direct purchasers will perceive direct purchasing as a more convenient shopping method than non-direct purchasers.

H3: Direct purchasers will have a significantly higher mean score than non-direct purchasers in terms of their perception that direct purchasing via mail is more private than purchasing in shops.

H4: Direct purchasers will have a significantly higher mean score than non-direct purchasers in terms of their perception that direct purchasing via telephone is more private than purchasing in shops.

H5: Direct purchasers will have a lower general risk perception regarding direct purchasing than non-direct purchasers.

H6: Direct purchasers will perceive lower financial risk in direct purchasing than do non-direct purchasers.

H7: Direct purchasers will perceive lower performance risk in direct purchasing 
than do non-direct purchasers.

H8: Direct purchasers will perceive lower time-loss risk in direct purchasing than do non-direct purchasers.

H9: There will be a significant difference between direct purchasers and non-direct purchasers in terms of their motivation to purchase directly because of the special offer advertised.

H10: There will be a significant difference between direct purchasers and nondirect purchasers in terms of their motivation to purchase directly because of the free item offered with the product.

Only statistically significant differences resulting from the hypothesis testing are discussed in the results.

\section{RESULTS}

Hypothesis testing was performed and the results of the Mann-Whitney test for each hypothesis as well as the mean values of the different groups are presented below.

\section{H1: Direct purchasers perceive direct purchasing as a shopping method that saves time}

The mean attitude score for the direct purchasers $(\mathrm{M}=3.8)$ reflected a more positive attitude than the mean score for non-direct purchasers $(M=2.8)$, which is in accordance with Hypothesis 1 . The findings from the Mann-Whitney test were significant ( $p=<0.001$ ), indicating that direct purchasers are more focused on saving time than non-direct purchasers. Changing consumer lifestyles in terms of a greater emphasis on extra time, more women entering the work force and the demand for more services and convenience affect the growth of direct purchases. With the evolution of dual-income households, the discretionary income of a particular household has increased, but the time in which to spend this money has decreased. Direct purchases can thus be seen as a time-saving strategy, since purchases can be done in the comfort of consumers' homes.

\section{H2: Direct purchasers perceive direct purchasing as a more convenient shopping method than non-direct purchasers}

Previous research suggests that direct purchasers find convenience to be a basic motivational factor for direct purchases. Direct purchasers have a definite need for, and place notable value on, convenience (James \& Cunningham, 1987). Convenience seems to increase in importance as a motivational factor as shopping time decreases. Even though some consumers find direct purchasing to be more convenience-orientated, many still find the waiting time for delivery after a product has been ordered directly to be inconvenient. The findings from the Mann-Whitney test for Hypothesis 2 were significant $(p<0.001$ ), indicating that direct purchasers do experience direct purchasing as being a convenient shopping method. Thus, in accordance with Hypothesis 2, the 
mean attitude score for direct purchasers $(\mathrm{M}=3.5)$ reflected a more positive attitude than the mean score for non-direct purchasers $(M=2.9)$.

$H 3 / 4$ : Direct purchasers will have a significantly higher mean score than non-direct purchasers in terms of their perception that direct purchasing via mail or telephone is more private than purchasing in shops

Some consumers may experience purchases via mail as private in nature, since they do not occur in a shopping environment. This may encourage direct purchases because these can be conducted in the privacy of consumers' own homes. The Mann-Whitney test for Hypothesis 3 revealed a significance ofp $<0.001$. As stated in the hypothesis, the test results indicate that direct purchasers do have a higher mean score $(M=3.5)$ than the mean score of non-direct purchasers $(\mathrm{M}=2.8)$. Just as some consumers may find purchases via mail to be private in nature, some may also find purchases via telephone to be private. This perceived privacy may be an encouragement to purchasing directly. The Mann-Whitney test for Hypothesis 4 also revealed a significance ofp $<0.001$. The mean scores indicate that direct purchasing via telephone is perceived as being more private by direct purchasers $(\mathrm{M}=3.6)$ than by non-direct purchasers $(\mathrm{M}=2.9)$.

\section{H5: Direct purchasers have a lower general risk perception regarding direct purchasing than non-direct purchasers}

In general, consumers tend to perceive higher risk and less convenience when purchasing via mail or telephone, as opposed to in-store shopping. This may be caused by the inability to inspect the product prior to purchase. The Mann-Whitney test for Hypothesis 5 revealed a significance ofp $<0.001$. The non-direct purchasing group $(\mathrm{M}=3.3)$ experienced higher general risk relating to direct purchasing than the direct purchasing group $(\mathrm{M}=2.2)$. This may be due to a negative experience or unsatisfactory encounter. Various writers discuss different types of perceived risk, for example, financial risk, performance risk, social risk and time-loss risk (McCorkle, Planchon \& James, 1987; Power, Balderstone \& Gyles, 2000). These different types of perceived risk were all tested and Hypotheses 6, 7 and 8 resulted in statistically significant outcomes.

H6/7/8: Direct purchasers perceive lower financial/performance/ time-loss risk in direct purchasing than do non-direct purchasers

Direct purchasers are confronted with various types of perceived risk because they cannot evaluate the product prior to the purchase, whereas in the case of traditional 
in-store purchases, they can. Direct purchasers have to rely on what has been printed, illustrated or claimed in printed material when they purchase directly. Direct marketers should pay special attention to perceived financial risk (initial cost of the product and possible expenses to repair, maintain or return the purchased product), and the time-loss risk (time lapse between ordering and receiving the product purchased, or the waiting time for returned goods to be repaired or replaced). Methods of risk reduction could include offering liberal return policies, free return postage and after-sales support. The results from the perceived financial risk, performance risk, and time-loss risk hypotheses indicated lower risk perceptions among direct purchasers than non-direct purchasers. The mean attitude score for direct purchasers $(M=2.4)$ on their financial risk perception was lowerthanthe mean score for non-direct purchasers $(M=3.3)$. In accordance with the hypothesis on performance risk, the mean attitude score for direct purchasers ( $\mathrm{M}=2.2$ ) was also lower than the mean score for non-direct purchasers $(M=3.1)$. Hypothesis 8, on time-loss risk perception, coincided with the previous hypothesis and again the mean attitude score for direct purchasers $(M=1.9)$ was lower than the mean score for non-direct purchasers $(M=2.7)$. The Mann-Whitney tests for Hypotheses 5, 6, 7 and 8 all indicated a significant difference ofp $<0.001$. The significant differences in the test results make sense because all respondents have purchased directly before, whereas the non-direct purchasing group was classified according to the response that they would not buy directly again.

$H 9 / 10$ : There is a significant difference between direct purchasers and nondirect purchasers in terms of their motivation to purchase directly because of the special offer advertised or the free item offered with the product

Atypical direct-response advertisement delivers a sales pitch with an additional special offer and invites the consumer to order via a toll-free number. Offering an incentive or free item with the advertised product may tempt consumers to buy impulsively. The results from the hypotheses testing indicate that direct purchasers are enticed to make a purchase when special offers $(p<0.001)$ or free items $(p<0.001)$ are offered. The mean attitude score for direct purchasers $(\mathrm{M}=3.5)$ regarding their motivation to buy directly if a special offer is made was higher than the mean score for non-direct purchasers $(M=3.0)$. In accordance with the hypothesis on offering a free item, the mean attitude score for direct purchasers $(\mathrm{M}=3.2)$ was also higher than the mean score for non-direct purchasers $(\mathrm{M}=2.7)$.

As mentioned before, only significant differences resulting from the hypotheses testing are discussed in this article. The following factors did not indicate statistical differences between direct purchasers and non-direct purchasers: perceived social risk, variety of products available, price consciousness, credit-card usage, purchase urgency built into advertisements and the use of toll-free numbers in the marketing offer. 


\section{Discriminant analysis}

The above hypotheses tests were followed by a stepwise discriminant analysis to determine how well the ten meaningful variables addressed in the Mann-Whitney testing discriminated between direct purchasers and non-direct purchasers. The analysis was carried out with the P7M programme of the BMDP software package. The first step was to establish two mutually exclusive groups. Accordingly, the sample was divided into two groups: direct purchasers (Group 1) and non-direct purchasers (Group 2).

A stepwise discriminant function analysis was used to build a step-by-step model of discrimination. In this analysis, the predictor variables are entered sequentially, based on their ability to discriminate among groups. An .F-ratio is calculated for each predictor by conducting a univariate analysis of variance in which the groups are treated as the categorical variable and the predictor as the criterion variable. The predictor with the highest .F-ratio is the first to be selected for inclusion in the discriminant function, if it meets certain significance and tolerance criteria. A second predictor is then added, based on the highest adjusted or partial .F-ratio, taking into account the predictor already selected. Each predictor selected is tested for retention, based on its association with other predictors selected. The process of selection and retention continues until all predictors meeting the significance criteria for inclusion and retention have been entered in the discriminant function (Malhotra, 1996).

To be included in the discriminant function, the direct-purchasing variables had to pass a tolerance test. The tolerance test, a stepwise procedure, was used to eliminate direct-purchasing variables that had small (less than 0.001) unique contributions or that correlated highly with other variables. Wilks's lambda was used as the criterion for the order of inclusion and for the decision whether a variable was to be included at all. Four variables were not included because there was no significant reduction of Wilks's lambda at a significance level of 5\%. Because there were two groups, only one discriminant function was estimated. The eigenvalue associated with this function is 0.3 , and accounts for $100 \%$ of the explained variance. The canonical correlation associated with this function was 0.48 , indicating that $23 \%$ of the variance in the dependent variable (direct-purchasing groups) was explained or accounted for by this model.

Before interpreting the analysis, the discriminant functions estimated have to be statistically significant. In BMDP, the test of the null hypothesis is based onanF transformation of Wilks's lambda. With a/?-value of/? $<0.001$, the resulting Wilks's lambda value of 0.77 is highly significant, indicating that mean test scores among the two groups are statistically different at significance levels exceeding 0.01 . The rejection of the null hypothesis indicates significant discrimination, serving as an indication to proceed with analysis and result interpretation. An examination of the absolute magnitude of the standardised discriminant function coefficients provides some idea of the relative importance of the variables.

Table 1 summarises the six standardised canonical discriminant coefficients that met the significance criteria for inclusion and retention. These standardised canonical 
discriminant function coefficients describe the relative contribution of each direct-purchasing criterion in determining the selection or non-selection of a product by direct purchasers (the larger the magnitude, the greater the contribution). The canonical correlation coefficient judges the substantive utility of the direct-purchasing criteria (discriminant function) by measuring the association between the set of direct-purchasing criteria and the selection of direct purchasers. The coefficient varies between 0 and 1 . A value of 0 denotes no relationship while larger values represent increasing degrees of association.

Table 1. Standard canonical discriminant function coefficients

\begin{tabular}{|lc|}
\hline Direct purchasing variables & Coefficient \\
\hline General risk & 0.40 \\
Performance risk & 0.33 \\
Save time & 0.32 \\
Time loss risk & 0.31 \\
Special offer & 0.30 \\
Mail is more private & 0.23 \\
\hline
\end{tabular}

Table 1 indicates that general risk, performance risk and time-saving dimensions are the most powerful discriminators among the six measured dimensions. The privacy of the mail dimension appears to make the smallest contribution. The convenience, telephone privacy, financial risk and free-item dimensions did not meet the significance criteria for inclusion and retention in the stepwise discriminant function analysis. The final criterion for assessing the discrimination value is the percentage share of cases that would be classified correctly on the basis of the discrimination functions. Table 2 shows the results in a classification matrix.

Table 2. Classification matrix

\begin{tabular}{|lcc|}
\hline Actual group & Predicted group 1 (\%) & Predicted group 2 (\%) \\
\hline Direct purchasers $(n=190)$ & 71 & 29 \\
Non-direct purchasers $(n=139)$ & 27 & 73 \\
\hline
\end{tabular}

The results reflected in Table 2 indicate that for the direct-purchasing group, $71 \%$ of the variables were correctly classified. For non-direct purchasers, $73 \%$ were correctly classified. The variables indicate a relatively high degree of successful prediction as to which purchasers will buy directly again and which will not, with these groups being accurately classified $72 \%$ of the time. 


\section{DISCUSSION}

The findings of the research survey have thus identified some of the salient motives of direct purchasers. The following conclusions can be drawn from the results of the study: (a) direct purchasers tend to perceive a lower risk in direct purchasing than non-direct purchasers; (b) the time saved in direct purchasing serves as a motivation to direct purchasers; (c) a special offer, be it a lower price, a bonus article or free item, serves as an incentive to purchase directly; and (d) privacy when using direct mail or telephone serves as a motivation to direct purchasers.

This study has shown that the factors motivating consumers to purchase directly correlate well with certain of the previous research findings. However, the findings of this study should be interpreted cautiously, bearing the exploratory nature of the research in mind. The study clearly indicates that perceived risk is one of the most definite discriminators between direct purchasers and non-direct purchasers. Direct marketers should thus focus on addressing consumers' perceived-risk perceptions.

Direct marketers must be able to target their offers and communications precisely to meet the wants and needs of different markets. To do this, direct marketers should consider following a needs-based segmentation approach in the design and implementation of segment-specific marketing and communication strategies. Future research on segmentation can assist marketers in matching underlying motives of potential prospects with their descriptive characteristics (Peltier \& Schribrowsky, 1992). This can lead to communication approaches that are better targeted and clearer offers by direct marketers to different market segments, and may lead to increased purchasing through direct-marketing media.

This study is limited in that it cannot be generalised to the South African population, as the composition of the sample was limited. This was because respondents were drawn from the client base of a direct-insurance company. The respondents were consequently representative of purchasers who had purchased service products directly, and the profile of this group may differ from purchasers who have purchased physical products on a direct basis.

Owing to restrictions in time and money, the study was of a limited exploratory nature and further research needs to be conducted to gain an in-depth knowledge of the factors affecting direct purchasing. Differences in media usage were not measured, meaning that it is not known whether people who buy telephonically will also necessarily purchase through the mail or Internet and vice versa. The findings of the study do not therefore provide a clear profile of the typical South African direct purchaser. Further research is needed to obtain a more comprehensive profile of direct purchasers in South Africa, and longitudinal research is needed to measure how consumers' propensity toward direct purchasing changes overtime.

As is evident from this study, the South African direct-marketing industry is in need of more conceptual and empirical research on the principles of buying motives. 
Unfortunately, this area of research has not drawn enough interest from South African researchers. Any relevant research would be invaluable to both researchers and marketers, since it can improve the marketing strategies of direct-selling companies.

\section{CONCLUSION}

Although sales of directly marketed products have been increasing, future growth will require aggressive direct-marketing strategies built on an understanding of targeted consumers' attitudes. The research demonstrates that the attitudes of direct purchasers and non-direct purchasers are significantly different on six dimensions. These include general risk, performance risk, time-loss risk, the benefit of saving time, receiving special offers and the benefit of shopping in a private environment when purchasing through direct mail. Consumers' attitudes to perceived risk and time-saving dimensions correlate with several previous research findings. The study strongly suggests that direct marketers should pay attention to lowering the perceived risk involved in direct purchasing. Despite direct marketing's potential, most direct marketers fail to optimally understand and exploit the unique nature of their buyers and markets. Clearly, further research is needed to examine and develop consumer profiles that indicate both purchasing and purchaser characteristics more definitively.

\section{ACKNOWLEDGEMENT}

The help of Ms Rina Owen of the Department of Information Technology at the University of Pretoria with data processing is hereby acknowledged.

\section{REFERENCES}

Akhter, S. H. and Durvasula, S. (1991). Consumers' attitudes toward direct marketing and purchase intentions. Journal of Direct Marketing, 5(3), 48-56. Anon (1993). The destiny on direct: A new perspective on the future of direct marketing. Journal of Direct Marketing, 7(4), 65-69. — . (2001). Direct Marketing Association, http://www.dma.org.za. Belch, G. E. and Belch, M. A. (1990). Introduction to advertising and promotion - an integrate

marketing communications perspective (2nd ed.). Boston: Richard D. Irwin. Berry, L. R. and Cooper, L. R. (1990, April-June). Competing with time saving services.

Business, 3-7. Crumbley, J. (1994, April). Building an image via direct response. Direct Marketing Magazine,

23-25. Cunningham, C. M. and Cunningham, W. H. (1973). The urban in-home shopper: socio-economic and attitudinal characteristics. Journal of Retailing, 49 (Fall), 42-50.

Donthu, N. and Gilliland, D. (1996). Observations: the infomercial shopper. Journal of Advertising Research, 36(2), 69-76. Eastlick, M. A. and Feinberg, R. A. (1994). Gender differences in mail-catalogue patronage motives. Journal ofDirect Marketing, 8(2), 37-45. Gauthronet, S. and Drouard, E. (2001, January). Unsolicited commercial communications and data protection. Commission of the European Communities, http://europa.eu.int/comm/ 
intemal_market/en/dataprot/studies/spam.htm. (accessed 12 July 2001). Ghert, K. C,

Yale, L. J. and Lawson, D. A. (1996). The convenience of catalogue shopping:

is there more to it than time? Journal of Direct Marketing, 10(4), 19-29. Holtz, H.

(1986). The direct marketer's workbook. New York: John Wiley and Sons. Humphrey, R.

(2000). Crime and confidence: voters' perceptions of crime. NedcorISS Crime

Index, 4(2), 2-5. James, E. L. and Cunningham, I. C. M. (1987). Aprofile of direct marketing television shoppers.

Journal of Direct Marketing, 7(2), 41-51. Jarvenpaa, S. L. and Todd, P. A. (1997).

Consumer reactions to electronic shopping on the

World Wide Web. International Journal of Electronic Commerce, 1(2), 59-88.

Jayawardhena, C, Wright, L. T. andMasterson, R. (2003). An investigation of online consumer purchasing. Qualitative Market Research: An International Journal, 6(1), 58-65.

Kaufman-Scarborough, C. and Lindquist, J. D. (2002). E-shopping in a multiple channel environment. Journal of Consumer Marketing, 19(A), 333-350. Kinnear, T. C. and

Taylor, J. R. (1996). Marketing research: an applied approach (5th ed.).

McGraw-Hill: New York. Lavin, M. (1992). Have contemporary consumers integrated

mail/phone order into their

categorisation of goods and retailers? Journal of Direct Marketing, 6(3), 22-31. - .

(1993). Wives' employment, time pressure, and mail/phone order shopping. Journal of

Direct Marketing, 7(1), 42-49. Long, G, Hogg, M. K., Hartley, M. and Angold, S. J.

(1999). Relationship marketing and

privacy: Exploring the thresholds. Journal of Marketing Practice, 5(1), 4-20. Malhotra,

N. K. (1996). Marketing research: An applied orientation (2nd ed.). New Jersey:

Prentice-Hall. Mann, L. (1997). The development of a privacy scale. Research report for

Master of Business

Administration, University of Cape Town. McCorkle, D. E., Planchon, J. M. and James, W. L. (1987). In-home shopping - a critical

review and research agenda. Journal of Direct Marketing, 1(2), 5-19. McDonald, W J.

(1993). The roles of demographics, purchase histories, and shopper decision-making styles in predicting consumer catalogue loyalty. Journal of Direct Marketing,

7(3), 55-65. Milne, G. R. and Gordon, M. E. (1994). A segmentation study of consumers' attitudes toward

direct mail. Journal of Direct Marketing, 8(2), 45-53. Park, C. H. and Kim, Y. G.

(2003). Identifying key factors affecting consumer purchase

behaviour in an online shopping context. International Journal of Retail \& Distribution Management, 31(1), 16-29. Park, J. H. and Stoel, L. (2002). Apparel shopping on the

Internet. Journal of Fashion Marketing

and Management, 6(2), 158-176. Peltier, J. W and Schribrowsky, J. A. (1992). The use of

need-based segmentation for developing segment-specific direct marketing strategies. Journal of Direct Marketing, 6(3), 44-53.

Phelps, J., Nowak, G. and Ferrel, E. (2000). Privacy concerns and consumer willingness to provide personal information. Journal of Public Policy \& Marketing, 19(1), 27-53.

Power, M., Balderstone, B. and Gyles, S. (2000). Direct Marketing. Sydney: McGraw-Hill.

Prabhaker, P. R., Sheehan, M. J. and Coppett, J. I. (1997). The power of technology in business selling: call centres. Journal of Business and Industrial Marketing, 12(3), 222-233. 
Reynolds, F. D. (1974, July). An analysis of catalogue buying behaviour. Journal ofMarketing, 38, 47-51. Roberts M. L. and Berger, P. D. (1999). Direct marketing management (2nd

ed.). Englewood

Cliffs, New Jersey: Prentice-Hall. Roberts, S., Feit, M. and Bly, R. W. (2001). Internet

Direct Mail: the complete guide to

successful e-mail marketing campaigns. Chicago, Illinois: NTC Publishing Group.

Sahd, B. G. (1998). Understanding and measuring privacy in the information age: the refinement and application of a privacy scale. Research report for Master of Business Administration, University of Cape Town. Schoenbachler, D. D., Gordon, G. L, Foley,

D. and Spellman, L. (1997). Understanding consumer database marketing. Journal of Consumer Marketing, 14(1), 5-19. Settle, R.

B., Alreck, P. L. and McCorkle, D. E (1994). Consumer perceptions of mail/phone order shopping media. Journal of Direct Marketing, 8(3), 30-45. Stewart, M. (1992).

The Canadian direct marketing handbook. Ontario: McGraw-Hill. Stone, B. (1979).

Successful direct marketing methods (2nd ed.). Chicago, Illinois: Crain Books. Tapp, A. (1998). Principles of direct \& database marketing. London: Financial Times

Management. Terblanche, N. S., Boshoff, C. and Smit, E. v. d. M. (1999). Consumers' reasons forpurchasing

low involvement goods by mail catalogue: Preliminary measurement guidelines. South African Journal of Business Management, 30(3), 93-99. Thomas, B. and Housden, M.

(2002). Direct marketing in practice. Oxford: Butterworth

Heinemann. Vijayasarathy, L. R. and Jones, J. M. (2000). Print and Internet catalogue shopping: Assessing

attitudes and intentions. Internet Research: Electronic networking applications and policy, 10(3), 191-202. Wang, P. and Petrison, L. A. (1993). Direct marketing activities and personal privacy. Journal of Direct Marketing, 7(1), 7-19. 